\title{
O DESENVOLVIMENTO DA CRIATIVIDADE DO ALUNO DE LÍNGUA ESTRANGEIRA ATRAVÉS DO MODELO CREATES
}

\author{
The development of foreign language students' creativity via the CREATES model
}

Carlos Eduardo de Araujo PLACIDO, USP ${ }^{1}$

\begin{abstract}
RESUMO: Em um mundo pós-moderno (LYOTARD, 1986), a criatividade é uma característica cognitiva de grande importância para se experienciar, agir e refletir sobre esse mundo. Entretanto, como ela nos pode possibilitar experienciar, agir e refletir sobre esse mundo? A resposta pode estar no seu desenvolvimento prático e constante. $\mathrm{O}$ desenvolvimento da criatividade oportuniza a criação de novos produtos, a elaboração de novos serviços, a geração de novos empregos e, também, a melhoria substancial tanto do ambiente escolar quanto do potencial criativo do professor e do aluno. Mas, como o professor, no nosso caso específico, de língua estrangeira pode assegurar o desenvolvimento criativo de seus alunos? Para que o professor possa desenvolver a criatividade de seus alunos ele, primeiramente, deve saber identificar com que modelo de criatividade ele está tratando. Sendo assim, o objetivo principal deste artigo é o de investigar conceitos já estabelecidos na literatura sobre criatividade (POPE, 2005; LUBART, 2007) e propor a reflexão sobre outro modelo ainda pouco abordado, o modelo CREATES da psicóloga americana Shelley Carson (2011) e suas possíveis aplicabilidades nas aulas de língua estrangeira, mormente de língua inglesa.
\end{abstract}

PALAVRAS-CHAVE: Ensino de língua estrangeira; Criatividade; Modelo CREATES

ABSTRACT: In a post-modern world (LYOTARD, 1986), creativity is a cognitive characteristic of great importance to experience, act and reflect upon this world. However, how can it experience, act and reflect upon this world? The answer may be on its practical and constant development. The development of creativity gives opportunity to create new products, to deal with new services, to generate new jobs and it may also improve the schooling environment and the development of teachers and students' creative potentiality. But, how can the foreign language teacher, which is our case, ensure the creative development of his students? For the foreign language teacher to develop the creativity of his students, he should first be able to identify which model of creativity he is dealing with. Thus, the main objective of this article is to investigate concepts already established in the literature about creativity (POPE, 2005; LUBART, 2007) and then propose a reflection upon another, still little explored, model of creativity, the model CREATES, developed by the American psychologist Shelley Carson (2011) and its possible applicability in foreign language classes, especially in English language classes.

KEYWORDS: Foreign language teaching; Creativity; CREATES model.

\footnotetext{
${ }^{1}$ Doutorando em Estudos Linguísticos e Literários (USP). ceplacido@gmail.com
} 


\section{INTRODUÇÃO}

A maioria das pessoas possui um incrível computador na cabeça, computador esse com um potencial praticamente ilimitado para mudar suas próprias vidas, as vidas das outras pessoas, assim como o mundo que as rodeia. Esse "supercomputador" de grande capacidade de adaptação, transformação, compreensão e conexão é o cérebro humano.

A psicóloga Shelley Carson (2011) nos lembra de que desde os primórdios da existência humana, nossos cérebros vêm nos auxiliando mais diversos acontecimentos evolucionários como, por exemplo, o controle do fogo, a criação da roda, o levante das pirâmides no Egito Antigo, a descoberta da penicilina, o desenvolvimento da internet até a "conquista" da Lua.

Carson (2011) afirma a importância do cérebro humano ao compará-lo diretamente ao cérebro de uma tartaruga. Segundo ela, a tartaruga habita o planeta Terra há bem mais tempo do que o ser humano (ela tem cerca de 220 milhões de anos de existência). Entretanto, ela não evoluiu tão rápido como o ser humano. E é neste ponto que Carson nos questiona: “Então, o que nos diferencia da tartaruga?” E sua resposta é bem direta: “(...) nosso cérebro criativo. Nosso cérebro nos permite sentir, amar, pensar e, mais importante, criar."(2011, p. 22).

Portanto, um dos grandes pontos essenciais que nos diferenciam da tartaruga (e provavelmente de muitos outros animais) é o incomensurável (e ainda pouco pesquisado) potencial criativo presente em nossos supercomputadores. Mas o que Carson (2011) quer dizer com criativo e/ou criatividade?

\section{CONCEITOS ANTIGOS PARA O TERMO CRIATIVO E/OU CRIATIVIDADE}

De acordo com a pesquisadora Lis Chamberlain (2005), o termo criatividade se originou a partir do verbo latino creare, ou seja, ação de se iniciar, de se formular e/ou erigir. Só a partir do século XX é que se começa a ver a utilização do adjetivo criativo nos mais diversos textos (literários, históricos, teses, ensaios, etc.). E apenas no século XXI é que se percebe o uso, cada vez mais constante, do substantivo feminino criatividade, provindo da adição do sufixo -i-dade à palavra criativo.

Semanticamente falando, o historiador Rob Pope (2005) nos chama a atenção para outra característica importante presente, mormente, na palavra criatividade: o caráter 
divino. O conceito de criatividade e ser criativo esteve há séculos atrelado ao do Criador (sociedade monoteístas) ou Criadores (sociedades politeístas). Quase nunca ao ser humano.

Isso por quê? Para Pope (2005), segundo crenças antigas e da Idade Média, foi Deus (ou os Deuses) o criador de tudo e de todos, portanto o ser humano não tem capacidade de criar nada. Para os gregos, o ser humano só pode ser visto como um mediador ou nas palavras do próprio Platão: um recipiente, ou seja, um ser demiurgo.

Entretanto, o próprio Pope (2005) nos instiga a pensar diferente, corroborado também pela Carson (2011): a manipulação do fogo, a invenção da roda e mesmo a descoberta da penicilina foram "criações criativas" do ser humano.

Além disso, o psicólogo Todd Lubart (2007) adiciona outra característica a essa ideia antiga de criatividade: a completude. Segundo Lubart (2007), para os gregos antigos, toda criação deve ser vista como algo completo, finito. Tal pensamento excluía todo o processo na confecção de um vaso ou mesmo de um poema, por exemplo.

Em síntese, tanto para Pope (2005) quanto para Lubart (2007), há três características principais atribuídas à ideia antiga de criatividade que ainda podem ser identificados atualmente: divino, demiurgia e completude. Não obstante, tais conceitos começam a serem questionados a partir do século XX, por meio de estudos das áreas de psicologia, antropologia, sociologia e artes.

\section{CONCEITOS NOVOS PARA O TERMO CRIATIVO E/OU CRIATIVIDADE}

A partir do século $\mathrm{XX}$, diversos pesquisadores começaram a questionar as características de divindade, demiurgia e completude presentes na palavra criatividade. Um dos principais críticos foi o russo Lev Semenov Vygotsky. Vygotsky (1971) identifica na criança o potencial criativo e esse potencial é, na verdade, o resultado direto de diversas interações ocorridas desde a infância até a fase adulta.

Entretanto, essa interação não se dá naturalmente, ou seja, sem intervenção alheia. É sempre uma interação socializante, ou seja, é uma relação, comunicação e contato entre um ser menos inexperiente e um ser mais experiente. É também de extrema importância destacar aqui que essa interação não se consubstancia apenas entre seres de uma mesma espécie, mas ela pode ocorrer entre um ser e o seu habitat, meio ambiente. Destarte, a criatividade é vista como uma característica cognitiva, respeitante ao que Vygotsky 
(1971) denomina como sendo as funções psicológicas superiores, ligadas diametralmente ao desenvolvimento onto e filogenético do ser humano.

Csikszentmihalyi e Sawyer (1995), por sua vez, percebem a criatividade com um fenômeno psicossocial. O que isso quer dizer? Csikszentmihalyi e Sawyer (1995) acreditam que a criatividade além de ser uma característica cognitiva (inerente ao supercomputador humano: o cérebro), ela é desenvolvida (e deve ser desenvolvida) por meio de diferentes trocas interpessoais, trocas essas sempre entre os mais diversos seres das mais diversas comunidades, incluindo seus respectivos meios.

Em um caminho parecido, Mitján Martínez (2012) assevera que a criatividade é também uma área de resolução de problemas. Mas o que isso quer dizer? Segundo Martínez (2012), todo ser criativo evolui, desenvolve-se por meio de desafios postos a sua frente.

Para exemplificar seu ponto de vista, Martínez (2012) cita Alexander Fleming, o descobridor da penicilina, que descobriu sua grande "descoberta" por "acaso". Em 1928, Fleming ao sair de férias, deixou por esquecimento algumas placas com culturas de micro-organismos em seu laboratório. Ao retornar, ele percebeu que uma das suas culturas fora contaminada por um bolor, mas ao seu redor, não havia mais bactérias. Com isso, Fleming descobriu um fungo do gênero Penicillium. No acaso, a descoberta.

Entretanto, Martínez (2012) ainda comenta que o acaso só favorece os espíritos preparados e não prescinde a observação, ou seja, Fleming só conseguiu descobrir por acaso a penicilina por ter o conhecimento para tal ato. Frente à tentativa de descobrir um novo medicamento, ele usou sua criatividade para resolver o problema posto.

Em um mundo pós-moderno (LYOTARD, 1986), percebe-se que as características de divindade, demiurgia e completude vão sendo paulatinamente questionadas e revisitadas. O foco da criatividade então passa a se dar no ser humano. Ele é o autor de seus atos criativos. Tais atos não são consubstanciados rapidamente e de forma imutável, eles passam por uma pletora de transformações ate chegar a um estágio apresentável. Mesmo assim, esse estágio apresentável pode indicar mudanças e, até mesmo, desenvolver-se ainda mais por meio de novos estudos e pesquisas.

Se a criatividade é uma característica cognitiva do ser humano, o ser humano é seu autor responsável e ela ocorre através de constantes processos de aperfeiçoamento, isso quer dizer que ela pode ser treinada, praticada e, por conseguinte, desenvolvida em qualquer ser humano hábil mediante um ser mais experiente (no nosso caso, o professor 
de língua estrangeira). Mas como o professor de língua estrangeira conseguiria substancializar esse desenvolvimento criativo? E é exatamente nesta esteira que Carson (2011) propõe o modelo CREATES.

\title{
O MODELO CREATES E POSSÍVEIS APLICAÇÕES EM AULAS DE LÍNGUA ESTRANGEIRA
}

De acordo com a Dra. Shelly Carson, da Universidade de Harvard nos Estados Unidos da América, o modelo CREATES é um bloco de técnicas de ativação neural. Esse conjunto de combinações estimula o cérebro humano a permanecer (por um determinado tempo) em um tipo de estado fisiológico de criatividade. Sendo assim, qualquer ser humano hábil (sem acefalias ou outros problemas cerebrais) pode desenvolver conscientemente seu potencial criativo e usá-lo nas mais diferentes áreas, inclusive nas salas de aula de língua estrangeira.

O modelo CREATES prevê sete modos operacionais do cérebro. Esses sete modos podem ser instigados e melhorados por meio de exercícios simples. Entretanto, esses exercícios devem ser praticados constantemente para que se verifiquem resultados contundentes. Esses sete modos, em inglês, são:

\author{
CONNECT (conectar) \\ REASON (razão) \\ ENVISON (visualizar) \\ ABSORB (absorver) \\ TRANSFORM (transformar) \\ EVALUATE (avaliar) \\ STREAM (corrente)
}




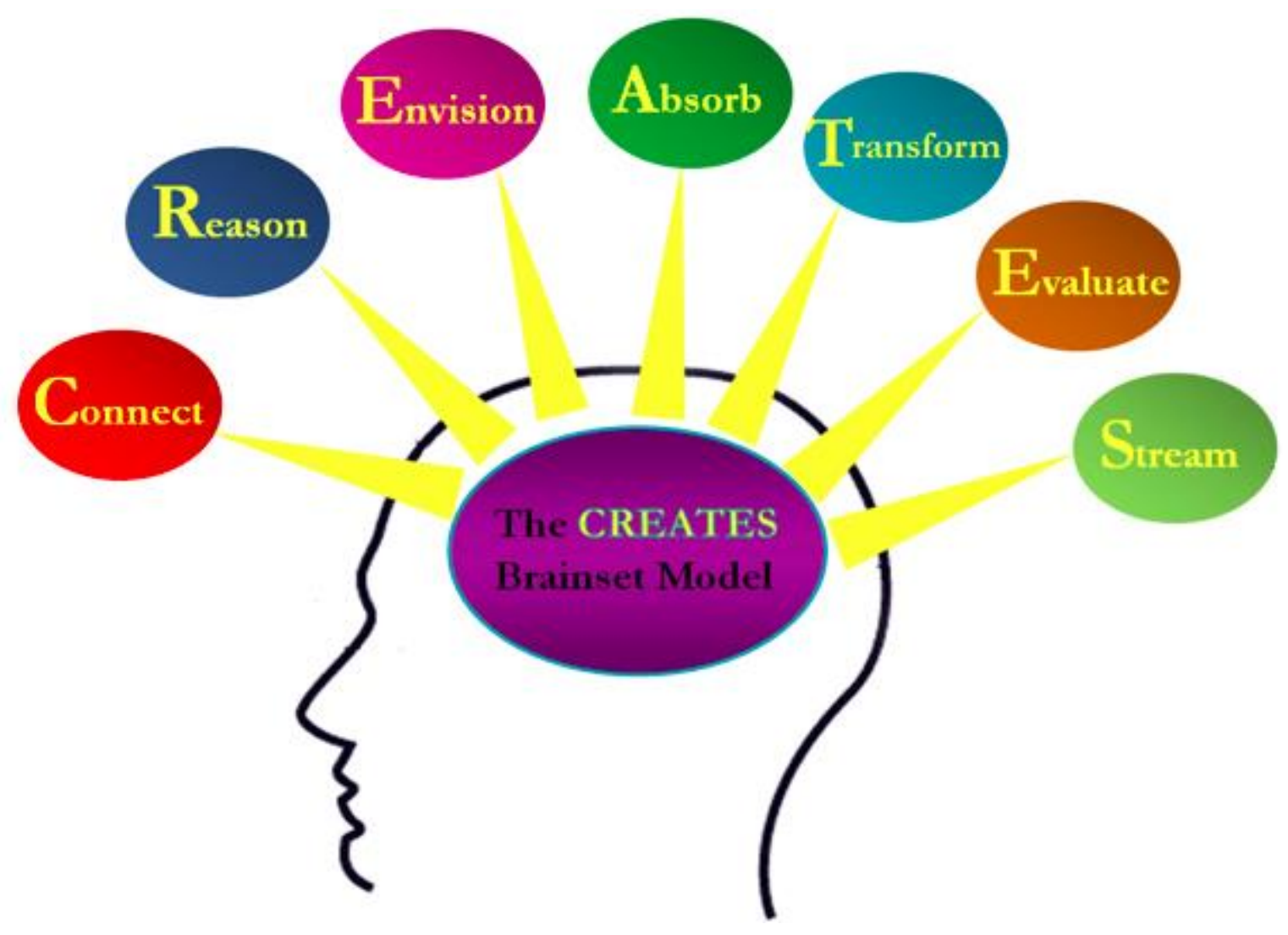

FIGURA $1^{2}$

De acordo com Carson (2011, p. 33), o modo conectar (connect, em inglês) possibilita ao aluno de língua estrangeira se desfocar, redirecionar sua atenção sobre uma questão e lhe permite também efetuar novas conexões entre conceitos aparentemente distintos. Tais características são importantes na gestação de múltiplas soluções para um problema específico. Por exemplo, o treinamento constante deste modo pode ser feito através de exercícios de elaboração de Mapas Mentais.

De acordo com Walther Hermann e Viviani Bovo (2005), os mapas mentais são um tipo de "diagrama hierarquizado de informações" (HERMANN \& BOVO, 2005, p. 04) utilizado principalmente por aqueles que necessitam identificar relações entre informações de forma rápida e eficaz. Uma forma rápida e eficaz (além de ser gratuita) de criar mapas mentais com os alunos de língua estrangeira é por meio do site https://bubbl.us/, como exemplificado a seguir:

${ }^{2}$ CARSON, SHELLY. Disponível em < http://www.shelleycarson.com/your-creative-brain/the-createsbrainset-model>. Acesso em 25/04/2016. 


\section{bubblous}

\section{Brainstorming made simple}

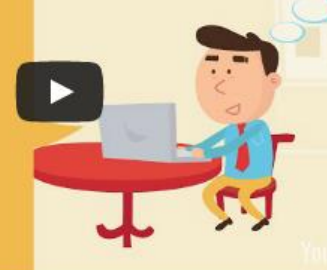

Start

Brainstorming

Learn more *

FIGURA $2^{3}$

Além de esse site ser de fácil manuseio, apresenta tutoriais para guiar seus usuários através da confecção de mapas mentais. A princípio, há duas formas simples de se confeccionar mapas mentais por meio do bubbl.us: 1) o usuário digita um tópico qualquer (comida, meio ambiente, educação, transporte, etc.) no retângulo central e o site lhe propõe palavras relacionáveis a esse tópico ou 2) o próprio usuário constrói toda a teia de relações com base na palavra colocada no retângulo central.

Já o modo seguinte, razão (reason, em inglês) deve ser instigado para aperfeiçoar tanto a aprendizagem de língua estrangeira quanto o próprio raciocínio lógico. $\mathrm{O}$ foco desta característica criativa se dá pelo planejamento intencional concomitantemente à busca de resultados diferentes, ou seja, não pensado previamente ou apreendidos como rotineiros. O seu treinamento pode ser desenvolvido através de sessões de feedback. Para Mory (2004), feedback nada mais é do que um tipo específico de procedimento utilizado com a finalidade de informar o aluno sobre a agudeza (correctness, em inglês) de sua resposta já dada, resposta essa ligada principalmente a alguma pergunta que requeira diretamente informação instrucional.

\footnotetext{
${ }^{3}$ Disponível em < https://bubbl.us/>. Acesso em 25/07/2016
} 
Uma forma simples e direta para trabalhar com feedback nas aulas de língua estrangeira é através da lista Dos and Don'ts, onde o professor pontua o que necessita ser melhorado de seu aluno de forma clara e positiva, além de poder propor alternativas para as formas errôneas de seu alunado, como está exemplificado a seguir:

\section{Giving Positive Feedback}

Dos

- Be specific and sincere

- Give attention to progress

- Praise efforts and achievements

- Acknowledge improvements in poor performance

\section{Don'ts}

- Praise vaguely/generally

- Add "But"

- Over praise

- Patronise

- Be begrudging

FIGURA $3^{4}$

Com o modo vizualizar (envison, em inglês), o aluno de língua estrangeira tem como foco o pensamento não verbal, ele lida com as mais diferentes formas de imagens e construções metafóricas. Nos dias atuais, com uma pletora de abordagens sociossemióticos de gêneros textuais, o modo visualizar ganha grande relevância. Ele pode ser desenvolvido por meio da construção de gêneros textuais que mesclam harmoniosamente o verbal e o não verbal como, por exemplo, histórias em quadrinhos (comic books, em inglês). Uma forma rápida e eficaz de se trabalhar com histórias em quadrinhos em aulas de língua estrangeira é com o site www.makebeliefscomix.com:

4 Disponível em < http://www.slideshare.net/AnnMarieOGrady/giving-and-receiving-feedback-dathscpd>. Acesso em 20/07/2016 


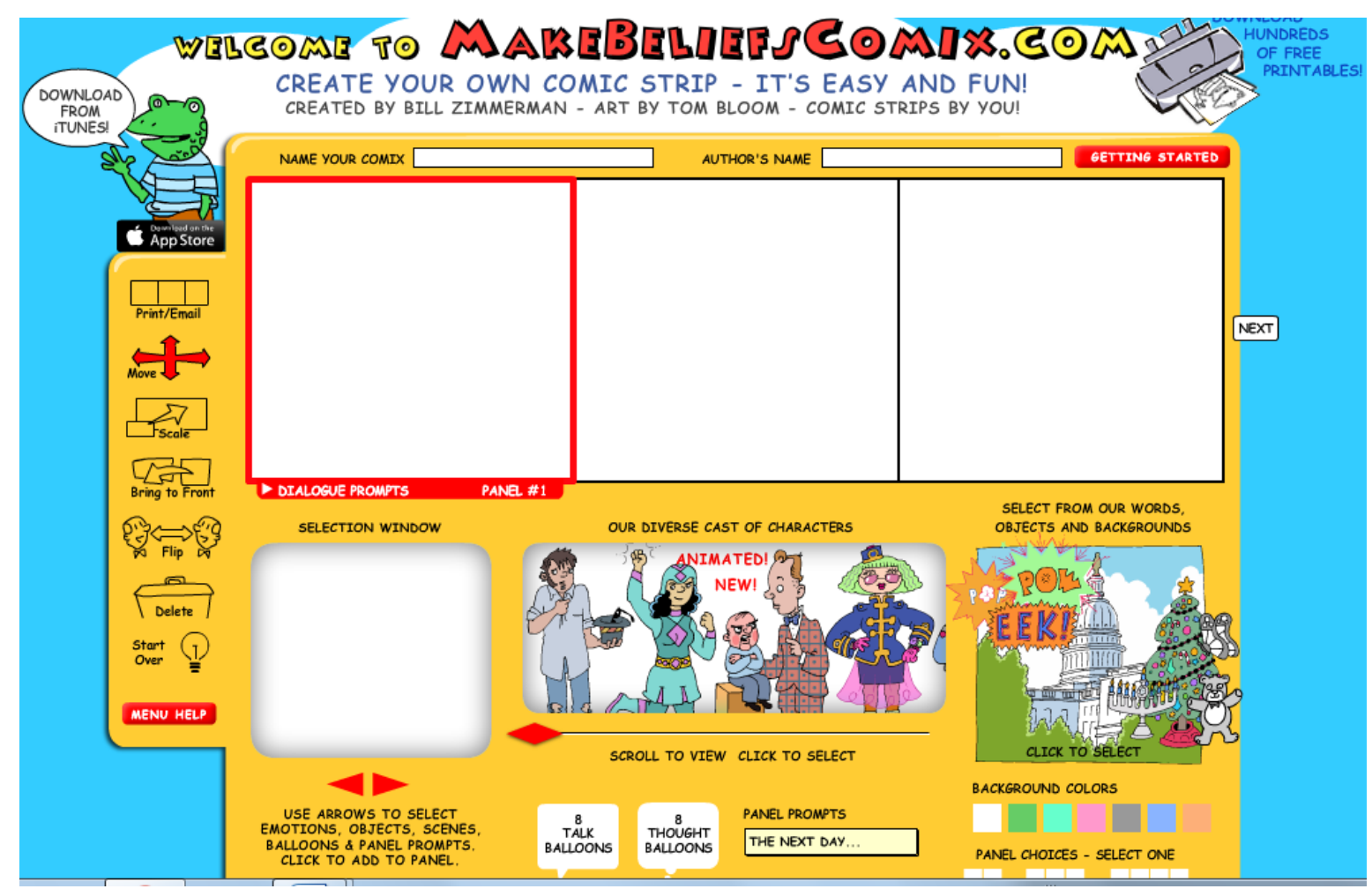

FIGURA $4^{5}$

Esse site apresenta vários recursos os quais podem ser utilizados pelos alunos de línguas estrangeiras na confecção de textos criativos em forma de histórias em quadrinhos. Um dos recursos mais interessantes é a opção de utilizar imagens disponibilizadas pelo próprio site ou imagens pessoais, ou seja, imagens criadas pelos próprios alunos. Esse recurso é interessante, pois muitos alunos podem não saber desenhar, o que se tornaria um empecilho na ministração dessa aula, por isso esse site fornece desenhos prontos. Entretanto, ele não se limita a isso, o que poderia podar a qualidade criativa daqueles alunos que sabem desenhar. Para que isso não ocorra, ele apresenta o recurso de compartilhamento de imagens pessoais.

O modo absorver (absorb, em inglês) direciona o cérebro humano para um estado de percepção plena e constante. Segundo Carson (2011), este modo tem a capacidade de identificar e, até mesmo, integrar conscientemente informações divergentes provindas diametralmente tanto do ambiente externo quanto interno de uma pessoa. $\mathrm{O}$ desenvolvimento do modo absorver é de grande relevância para a superação de bloqueios criativos como exercícios de confecção poética.

\footnotetext{
${ }^{5}$ Disponível em < http://www.makebeliefscomix.com/Comix/>. Acesso em 21/07/2016
} 
Entretanto, confeccionar poemas não é uma tarefa fácil, principalmente dentro do tempo limitado das aulas de língua estrangeira. Sendo assim, uma forma rápida e eficaz para se utilizar criação literária em sala de aula é por meio de site os quais possam auxiliar os alunos de forma clara a confecção de textos poéticos. Destarte, uma forma eficaz para se aprender uma língua estrangeira através de textos poéticos é na confecção de poemas acrósticos. Poemas acrósticos são um tipo de gênero literário que se baseia na formação de palavras ou, até mesmo, frases completas com as letras iniciais, medias ou finais. Uma forma interativa de se utilizar textos acrósticos em aulas de língua estrangeira é através do site Acrostic Poems:

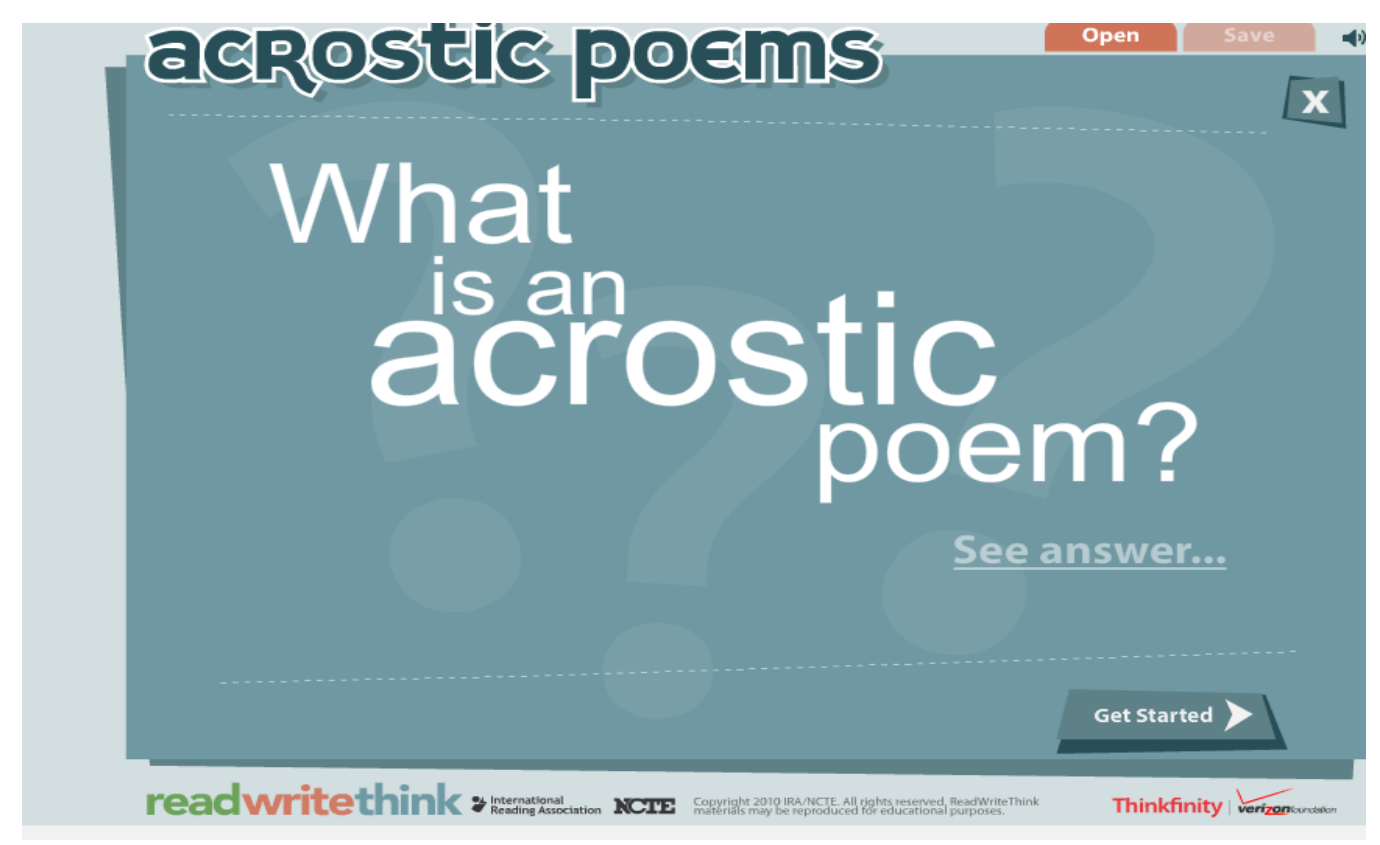

FIGURA $5^{6}$

Neste site, o aluno de língua estrangeira é disponibilizado com um passo a passo interativo para confeccionar seu próprio poema acróstico. $\mathrm{O}$ mais interessante deste site é que o aluno pode criar uma infinidade de poemas todos a partir de uma palavra base, chamada pelo site de topic. Sendo assim, indiferentemente do assunto trabalhado no livro didático, por exemplo, o professor de língua estrangeira pode utilizar esse site para auxiliar seu aluno tanto no desenvolvimento de seu potencial criativo através da confecção de um poema acróstico quanto como uma forma de prática de um determinado assunto trabalhado anteriormente em sala de aula.

\footnotetext{
${ }^{6}$ Disponível em < http://www.readwritethink.org/files/resources/interactives/acrostic//>. Acesso em 21/07/2016
} 
Como o próprio modo transformar (transform, em inglês) sugere, ele é o modo você capaz de recriar, reconfigurar, redefinir as fraquezas criativas dos alunos de língua estrangeira e a transformá-las em ferramentas criativas. O modo transformar foca em questões de sentimento como, por exemplo, raiva, tristeza, felicidade, angústias e inseguranças, isso porque muitos dos sentimentos humanos acabam por bloquear o pensamento criativo e afetam negativamente a capacidade de aprendizagem.

Um exercício frutífero para treinar esse modo é o de transformação de categorias gramáticas uma nas outras, ou seja, transformar verbos em substantivos, substantivos em adjetivos, adjetivos em advérbios, entre outras. O site English Language \& Usage disponibiliza exercícios gratuitos e interativos online para essa prática:

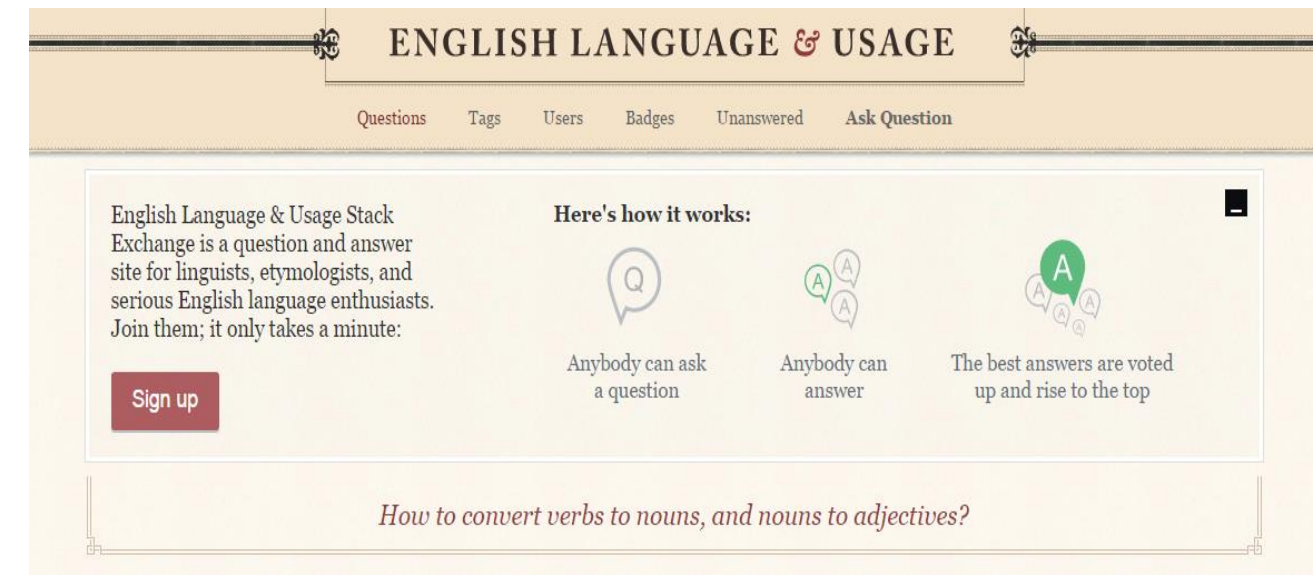

FIGURA $6^{7}$

De forma rápida e eficaz, esse site disponibiliza recursos pedagógicos para se trabalhar a transformação de categorias gramáticas, somente em língua inglesa, de diferentes formas. Talvez o mais interessante deste site seja o fornecimento de instruções claras as quais devem ser levadas em conta durante a transformação de uma categoria gramatical em outra. Ademais, ele ainda possibilita o armazenamento e compartilhamento dessas transformações, juntamente com a sua exemplificação em composições linguísticas mais complexas como frases e pequenos textos.

Já o modo avaliar (evaluate, em inglês) exercita essencialmente a capacidade de análise crítica do aluno de língua estrangeira juntamente com sua capacidade de escolha e edição de informações pertinentes para a elaboração de um determinado produto ou resolução de um problema específico. Além disso, ele também auxilia no

\footnotetext{
${ }^{7}$ Disponível em < http://english.stackexchange.com/>. Acesso em 24/07/2016
} 
desenvolvimento de filtros mentais. A análise de textos literários é um ótimo recurso para o aprimoramento deste modo. O site Close Reading of a Literary Passage propõe 5 passos básicos para se analisar qualquer passagem literária em uma aula de língua estrangeira:

\section{Close Reading of a Literary Passage}

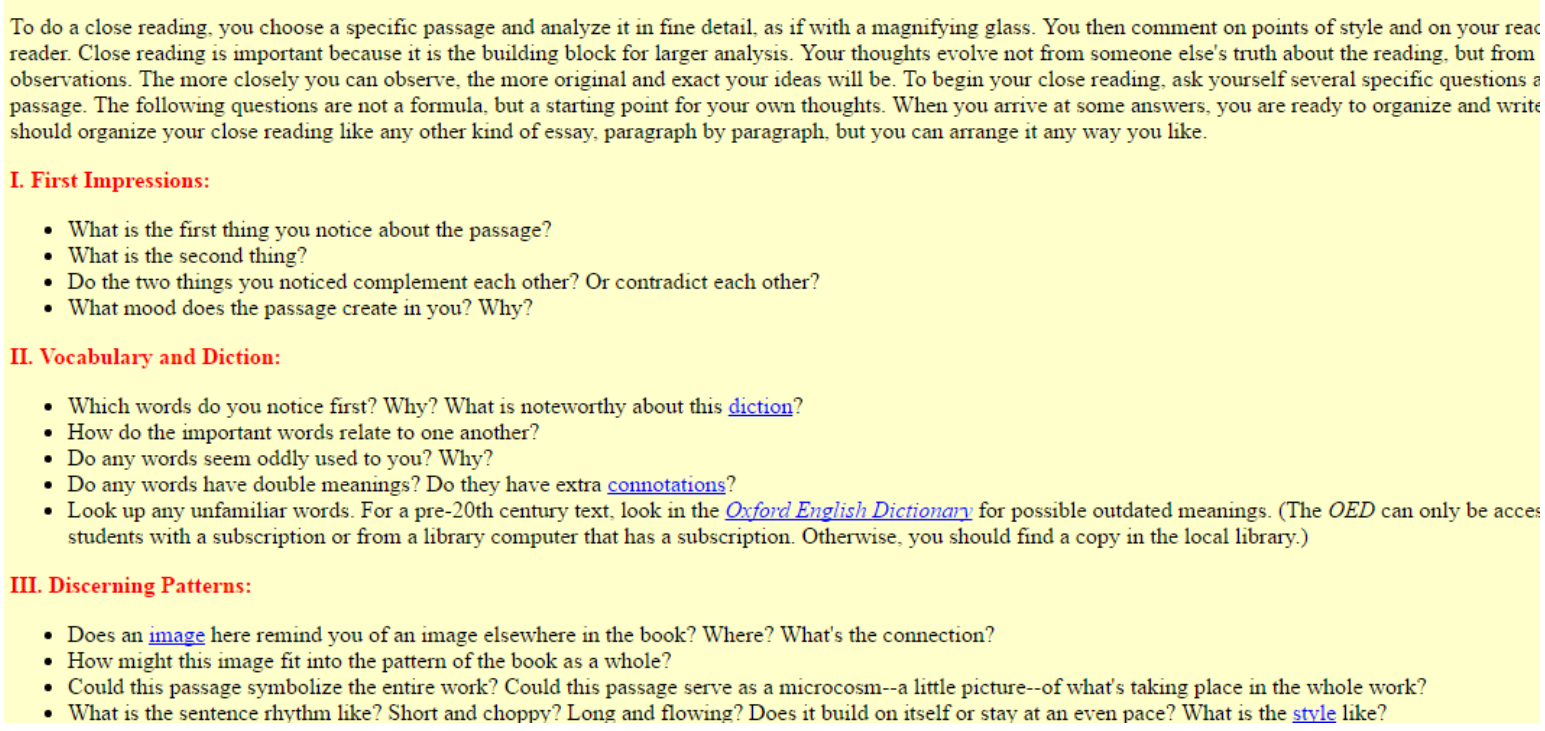

FIGURA $7^{8}$

O mais interessante deste site talvez seja a amplitude das perguntas propostas. Independentemente do texto literário escolhido (poesia, contos, passagens de romances, entre outros), o professor de língua estrangeira pode usá-las para que seus alunos possam exercitar o modo avaliar. Embora em muitos casos seja possível utilizar todas as perguntas indicadas no site, é aconselhável que o professor faça uma pré-leitura do texto literário a ser trabalhado em sala de aula e então filtre as perguntas mais adequadas.

E, por fim, há o modo corrente (stream, em inglês). Este modo configura um estado cerebral de improvisação, sendo capaz de produzir uma sequência harmoniosa e recorrente de ideias inovadoras. Com este modo, o aluno de língua estrangeira consegue explicitar e controlar mais conscientemente todo o seu fluxo criativo. Nem toda ideia é uma boa ideia, mas toda ideia pode se tornar uma boa ideia se for oportunizada e aprimorada. Um exercício eficaz para o desenvolvimento do modo corrente é a confecção

\footnotetext{
${ }^{8}$ Disponível em < https://web.cn.edu/kwheeler/reading_lit.html>. Acesso em 26/07/2016
} 
de histórias seriais. Histórias seriais são histórias que um aluno inicia a partir, por exemplo, de uma história já existente ou baseada em um objeto dado em sala de aula e, de forma subsequente, ou seja, serial, o outro (ou outros) continua a partir de onde o aluno anterior parou.

\section{CONCLUSÃO}

A pós-modernidade (LYOTARD, 1986) vem possibilitando o questionamento de vários termos (sexualidade, ciência, raça, etc..) tidos, a priori, como fixos e imutáveis. A criatividade é um desses termos. Como investigado nesse artigo, há diversos modelos para se compreender o termo criatividade nos dias atuais. É ainda possível compreendêlo pelo modelo antigo, ou seja, de divino, demiurgia e completude. Entretanto, o problema é compreendê-lo apenas através desse modelo. Por isso, a psicóloga americana Shelly Carson (2011) propõe outro modelo embasado na psicologia inatista, o modelo CREATES (CARSON, 2011). Esse modelo compreende a criatividade como sendo constituída de sete modos cerebrais (conectar, razão, visualizar, absorver, transformar, avaliar e corrente). Com isso, a criatividade é vista como uma qualidade cognitivista apta a ser identificada e desenvolvida por todos, salvo raras exceções (pessoas com distúrbios cerebrais sérios, por exemplo). Segundo Carson (2011), a criatividade pode ser identificada e desenvolvida em diversas áreas do saber humano, inclusive nas aulas de língua estrangeira. No caso das aulas de língua estrangeira, é importante para o professor de língua estrangeira identificar quais são os modos cerebrais mais "urgentes" de serem desenvolvidos e então propor atividades específicas (confecção de histórias em quadrinhos, sessões de feedback, aplicação de histórias seriais, etc..) para o desenvolvimento apropriado de cada um dos modos.

\section{REFERÊNCIAS BIBLIOGRÁFICAS}

CARSON, S. Seu Cérebro Criativo. Trad. Bruno Casotti. Rio de Janeiro: BestSeller, 2011.

CHAMBERLAIN, L. Creativity and literacy. In: WILSON, A. (Org.). Creativity in primary education. Exeter: Learning Matters, 2005. pp. 68-76. 
CSIKSZENTMIHALYI, M.; K. Sawyer. Creative Insight: The Social Dimension of a Solitary Moment. In: DAVIDSON, J. E.; STERNBERG, R.J. (Orgs.) The Nature of Insight. Cambridge, MA: MIT Press, 1995. pp. 329-363.

HERMANN, W. \& BOVO, V. Mapas Mentais - Enriquecendo inteligências. Disponível em $<$ http://www.idph.net/download/mmapresent.pdf $>$. Acesso em 20/07/2016.

LUBART, T. Psicologia da Criatividade. Porto Alegre: Artmed, 2007.

LYOTARD, J.F. O Pós-Moderno. Rio de Janeiro: José Olympio, 1986.

MITJÁNS M. A. Aprendizagem criativa: uma aprendizagem diferente. In: MITIJÁNS MARTÍNEZ, A.; SCOZ, B.J.L.; CASTANHO,M. I. S. (Orgs.). Ensino e aprendizagem: a subjetividade em foco. Brasília, DF: Liber Livros, 2012. pp.85-109.

MORY, E. H. Feedback research review. In: JONASSEM, D. (Comp.). Handbook of research on educational communications and technology. Mahwah: Lawrence Erlbaum, 2004. pp. 745-783.

POPE, R. Creativity: Theory, History and Practice. New York: Routledge, 2005.

VYGOSTSKY, L. S. Psicologia da Arte. São Paulo: Martins Fontes, 1971. 